\title{
Nonlinear Quadratic Fractional Transportation Problem for Optimal Solution Deduction
}

\author{
A. Sathesh, \\ Department of EEE, \\ Eritrea Institute of Technology, \\ Eritrea. \\ Email: sathesh4you@gmail.com
}

\begin{abstract}
The manifold non-linear programming problems (NLPP) are dealt by people in their daily routines in the form of real time uses. The non-linear problem could deliver a remedies on the problems that require decision making, for instance corporate planning as well as finance, production and marketing, sales and inventory etc. this makes the fractional programing a research area of predominance. The fractional programming in transportation problem of disposing a one type of goods to various endpoint with varying quantities would enable to identify probable solution at a minimized cost and duration. The paper with the research study on the one such NLPP is coined as the fractional-quadratic transportation problem. (FQTP). The NLPP are highly popular since they deliver a supreme depictions of distribution problems for the real-life applications were the transportation cost remains changing. The proposed strides in the paper emphasis on deducing the solutions that are optimal for such difficulty. The proposed algorithm is examined with the numerical instance to demonstrate the proficiency of the algorithm and its benefits in the transportation structure belonging to different area of application
\end{abstract}

Keywords: Non-Linear Programming, FOTP, Transportation Problems, Optimal Solutions, Decision Making

\section{Introduction}

The decision making in the real life causes people to much confusion as there are numerous of solution encompassed with pros cons are available nowadays. As people always aim for a cost effective solutions with heightened performance, the optimization structure including the objective functions is utilized. In case of a production unit the objective function cloud be a loss or a profit observed as result of planning under taken in finance and corporate or either sales or inventory or even something that is about the planning involved in the production or the marketing. In most cases the solution are devised using the fractional programming due to its supremacy in arriving to a perfect solution. It enables to achieve a cost effective solution for transporting as single type of goods available at various areas to various end points at a reasonable duration.

ISSN: 2582-2640 (online) 
Journal of Soft Computing Paradigm (JSCP) (2020)

Vol.02/ No.02

Pages: $92-100$

http://irojournals.com/jscp/

DOI: https://doi.org/10.36548/jscp.2020.2.002

All types of research in the area fall under scope of framing a method to identify a remedy or applying the remedy identified to achieve a proficient performance. With scope of limiting the or reducing the functions that are linear, according to the restrictions of the traditional transportation problem the author Mustafa, et al [1] devised a steps to attain the primary solutions for the similar problems such as the "Vogel's approximation method". Satya et al [2] put forward an objectives to be handled in the "transportation problem" to reduce the overall cost and the time taken for the completing the transportation.

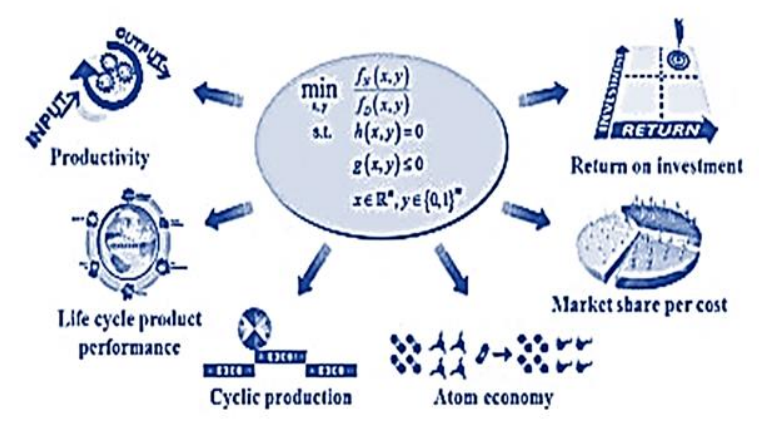

Figure.1 Application of fractional Programming [4]

Basu,M., et al [3] designed the model to obtain an optimal trade off with reasonable cost and time for managing the "fixed charge bi-criterion transportation problem" Schaible, et al [4] discusses the " three different types of the multi ratio fractional programs, (i) the maximization of the smallest ratios, (ii) maximization of sum ratios and the multi-objective fractional programs and the latest advancements were examined to identify the open problems in it. Venkata $S$ et al [5] took into consideration the dual functions that are non-linear as well as the restrictions in the probabilistic. The author Stancu-Minasian et al [6] elaborated the "procedures and the theory and the applications". M. H. Ifeyinwa et al [7] devised an OBJFUNC with the adding the linear as wells as the fractional-linear function.

Kavita, et al [8] proposed the model with the OBJ-FUNC formed with the linear and the fractional functions. Narayanamoorthy, S., et al [9] put forth the "decomposition strategy to solve the transportation problem using the fuzzy system forming the OBJ-FUNC as FFOF" Smys, S.,et al [10] put forth the "Efficient topology control in wireless networks using minimum Backbone updates." Rahimunnisa et al [11] devised the "Hybridized Genetic-Simulated Annealing Algorithm for Performance Optimization in Wireless Adhoc Network." Pandian, A. P et al [12] "Artificial Intelligence Application in Smart Warehousing Environment for Automated Logistics." Ananthi, J. Vijitha, devised the "A Peer to Peer Overlay Approach for Topology Maintenance in Wireless Networks."

ISSN: 2582-2640 (online) 
Journal of Soft Computing Paradigm (JSCP) (2020)

Vol.02/ No.02

Pages: $92-100$

http://irojournals.com/jscp/

DOI: https://doi.org/10.36548/jscp.2020.2.002

\section{Proposed Design of FQTP}

The section is about the mathematical formulation of the FQTP and the proposed algorithm in managing the transportation problem.

\subsection{Mathematical Design}

The Design put forth considers goods available in different source $(A)$ with varying quantities. The amount of goods in the $\mathrm{X}^{\text {th }}$ source is denoted as $a_{x}(1 \ldots \ldots A)$ and the demand in the $\mathrm{Y}^{\text {th }}$ destination $D$ is denoted as $d_{y}(1 \ldots \ldots D)$, so the $G x y$ is the amount of goods transported form $\mathrm{X}^{\mathrm{th}}$ source to the $\mathrm{Y}^{\text {th }}$ destination. The actual and the standard cost of the transportation from the source to the destination is denoted as the $A C_{x y}$ and $S C_{x y}$ respectively. The FQTP is mathematically indicated as shown in equation $1-4$

$$
=\frac{\left[\sum_{x=1}^{A} \sum_{y=1}^{D} A C_{x y} G x y\right]^{2}}{\left[\sum_{x=1}^{A} \sum_{y=1}^{D} S C_{x y} G x y\right]^{2}}
$$

The limitations are designed as

$$
\begin{aligned}
& \sum_{y=1}^{D} G x y=a_{x}(x=1 \ldots \ldots A) \\
& \sum_{x=1}^{A} G x y=d_{y}(y=1 \ldots \ldots D)
\end{aligned}
$$

So the

$$
\sum_{x=1}^{A} a_{x}=\sum_{y=1}^{D} d_{y}(x=1 \ldots \ldots A ; y=1 \ldots \ldots D)
$$

The mainly the design scopes in delivering another remedy procedure replacing the conventional for the FQTP.

The Steps below express the algorithm developed for the FQTP

ISSN: 2582-2640 (online) 
Journal of Soft Computing Paradigm (JSCP) (2020)

Vol.02/ No.02

Pages: $92-100$

http://irojournals.com/jscp/

DOI: https://doi.org/10.36548/jscp.2020.2.002

\subsection{Algorithm}

The proposed algorithm is provided for delivering optimal solutions for the FQTP is shown below in table .1

\begin{tabular}{|l|l|}
\hline Steps & Procedure \\
\hline 1. & $\begin{array}{l}\text { Identify the original primary options for solving the problem by using the "Vogel's } \\
\text { approximation method" as in [1] }\end{array}$ \\
\hline 2. & $\begin{array}{l}\text { The allotted amount of cell should not exceed the } A+D-1, \text { if exceeds update elements to } \\
\text { the cells that are independent and progresses. }\end{array}$ \\
\hline 3. & $\begin{array}{l}\text { Determine the two variables } i_{x}^{\prime}, i_{x}, j_{y}^{\prime}, j_{y}, \text { from the primary cells estimate the } A C_{x y}=i_{x}+j_{y} \\
\text { and the } S C_{x y}=i_{x}^{\prime}+j_{y}^{\prime}\end{array}$ \\
\hline 4. & $\begin{array}{l}\text { Determine the } A C_{x y}{ }^{\prime}=A C_{x y}-i_{x}-j_{y} \text { and the } S C_{x y}{ }^{1}=S C_{x y}-i_{x}^{\prime}-j_{y}^{\prime} \text { for all the other cells } \\
\text { other than primary. }\end{array}$ \\
\hline 5 & $\begin{array}{l}\text { Determine the changes happening in the cost incurred due to the due to the introduction of } \\
\text { other cells that are not primary, } A_{x y}=A C_{x y}{ }^{\prime} X R E \text { and } A_{x y}{ }^{1}=S C_{x y}{ }^{1} X R E, \text { where } \mathrm{RE} \text { is the } \\
\text { fundamental for the reallocation. }\end{array}$ \\
\hline 6 & $\begin{array}{l}\text { Determine the } \Delta_{x y}=2 v 1\left(v 2 * A_{x y} \text {-v }{ }^{*}{ }^{*} A_{x y}{ }^{1}\right) \text { where v1 }=\sum A C_{x y} G_{x y} \quad \text { and the } \mathrm{V} 2= \\
\sum S C_{x y} G_{x y}\end{array}$ \\
\hline 7. & $\begin{array}{l}\text { If } \Delta_{x y} \geq 0, \text { then the prevailing solution is assigned as optimal and the procedure is } \\
\text { terminated else go to step } 8\end{array}$ \\
\hline 8 & \begin{tabular}{l} 
Select -ve $\Delta_{x y}$ and improve the solution forming a closed loop Go To step 2 \\
\hline
\end{tabular} \\
\hline
\end{tabular}

Table.1 Proposed Algorithm for FQTP

ISSN: 2582-2640 (online) 
Journal of Soft Computing Paradigm (JSCP) (2020)

Vol.02/ No.02

Pages: $92-100$

http://irojournals.com/jscp/

DOI: https://doi.org/10.36548/jscp.2020.2.002

\section{Numerical Evaluation}

The performance of the above algorithm is examined using the real life application "the problem in shipping of goods" the logistics of the goods dispatching company with three various departments of processing. The processing is goods from three different ' $A$ ' has to reach ' $D$ ' and goods received from different sector is of different quality and quantity. The main scope is estimate prefect transportation that reduces the $A C_{x y}$ and $S C_{x y}$ of the shipping. The problem is defined mathematically using the equation 1 as

$$
=\frac{\left[\sum_{x=1}^{3} \sum_{y=1}^{3} A C_{x y} G x y\right]^{2}}{\left[\sum_{x=1}^{3} \sum_{y=1}^{3} S C_{x y} G x y\right]^{2}}
$$

And the limitations are formed using the equation $2-4$

$$
\begin{array}{r}
\sum_{y=1}^{3} G x y=a_{x}(x=1,2,3) \\
\sum_{x=1}^{3} G x y=d_{y}(y=1,2,3) \\
\sum_{x=1}^{3} a_{x}=\sum_{y=1}^{3} d_{y} \text { If } G x y \geq 0
\end{array}
$$

The table. 2 below shows the details of the work centers and the manufacturing units.

\begin{tabular}{|l|l|l|l|l|}
\hline & \multicolumn{3}{|l|}{ Goods Dispatching Unit } & $a_{x}$ \\
\hline \multirow{3}{*}{$\begin{array}{l}\text { Working } \\
\text { Centers }\end{array}$} & $A C_{11}=8$ & \multicolumn{1}{|l}{$A C_{12}=6$} & $A C_{13}=9$ & 12 \\
& $S C_{11}=3$ & $S C_{12}=2$ & $S C_{13}=1$ & \\
\cline { 2 - 5 } & $A C_{21}=5$ & $A C_{22}=4$ & $A C_{23}=5$ & 10 \\
& $S C_{21}=2$ & $S C_{22}=1$ & $S C_{23}=4$ & \\
\cline { 2 - 5 } & $A C_{31}=6$ & $A C_{32}=3$ & $A C_{33}=9$ & 8 \\
& $S C_{31}=3$ & $S C_{32}=2$ & $S C_{33}=4$ & \\
\hline$d_{y}$ & 5 & 16 & 6 & \\
\hline
\end{tabular}

Table.2 Data Used

ISSN: 2582-2640 (online) 
Journal of Soft Computing Paradigm (JSCP) (2020)

Vol.02/ No.02

Pages: $92-100$

http://irojournals.com/jscp/

DOI: https://doi.org/10.36548/jscp.2020.2.002

The primary solution, the two variables and the optimal solutions are obtained applying the algorithm the results observed is shown in the table. 3 below, the two variables enable to determine the possible RE in order to form the loops.

\begin{tabular}{|c|c|c|c|}
\hline \multirow{3}{*}{$\begin{array}{l}\text { Primary feasible } \\
\text { solution }\end{array}$} & $8 / 3=-$ & $6 / 2 G_{x y}=9$ & $9 / 1 G_{x y}=1$ \\
\hline & $5 / 2 \quad G_{x y=4}$ & $4 / 1$ & $5 / 4 G_{x y}=4$ \\
\hline & $6 / 3$ & $3 / 2 G_{x y}=6$ & $9 / 4$ \\
\hline Two variables & $\begin{array}{l}\mathrm{V} 1{ }^{\prime}=0 \\
\mathrm{~V} 1^{\prime}=0\end{array}$ & $\begin{array}{l}\mathrm{V} 2=-2 \\
\mathrm{~V}^{\prime}=3\end{array}$ & $\begin{array}{l}\mathrm{V} 3=0 \\
\mathrm{~V} 3{ }^{\prime}=2\end{array}$ \\
\hline \multirow{3}{*}{$\begin{array}{l}\Delta_{x y} \text { for non } \\
\text { primary cells }\end{array}$} & $-90,061$ & - & - \\
\hline & & 21,157 & - \\
\hline & $-50,161$ & - & 28,645 \\
\hline \multirow[t]{3}{*}{ Optimal Solutions } & - & - & 89,500 \\
\hline & - & 88,546 & - \\
\hline & 11,000 & - & 11,420 \\
\hline
\end{tabular}

Table.3 Primary and Optimal Solutions

The non-primary cells are estimated using the algorithm in table. 1 and the optimal solutions is attained if $\Delta_{x y} \geq 0$ else the negative $\Delta_{x y}$ is estimated and the closed to loop is formed to enhance the solution. So the average cost for shipping was estimated to be around 2800 after the application of the algorithm. The output attained was compared with the prevailing method that is conventional and was found to superior than it. The figure. 2 shows the cost incurred by the application of the proposed method under three different cases and the cost incurred by the conventional method.

The outcome achieved on the application of the proposed algorithm is highly proficient substantial for the cost optimization in the logistics/transportation issues compared to the conventional method. As the proposed method is a nonlinear fraction quadratic cost optimization for the transportation, it achieves

ISSN: 2582-2640 (online) 
Journal of Soft Computing Paradigm (JSCP) (2020)

Vol.02/ No.02

Pages: $92-100$

http://irojournals.com/jscp/

DOI: https://doi.org/10.36548/jscp.2020.2.002

superior results than the prevailing linear programming. The figure 2 provides the cost optimization achieved by the algorithm put forth.

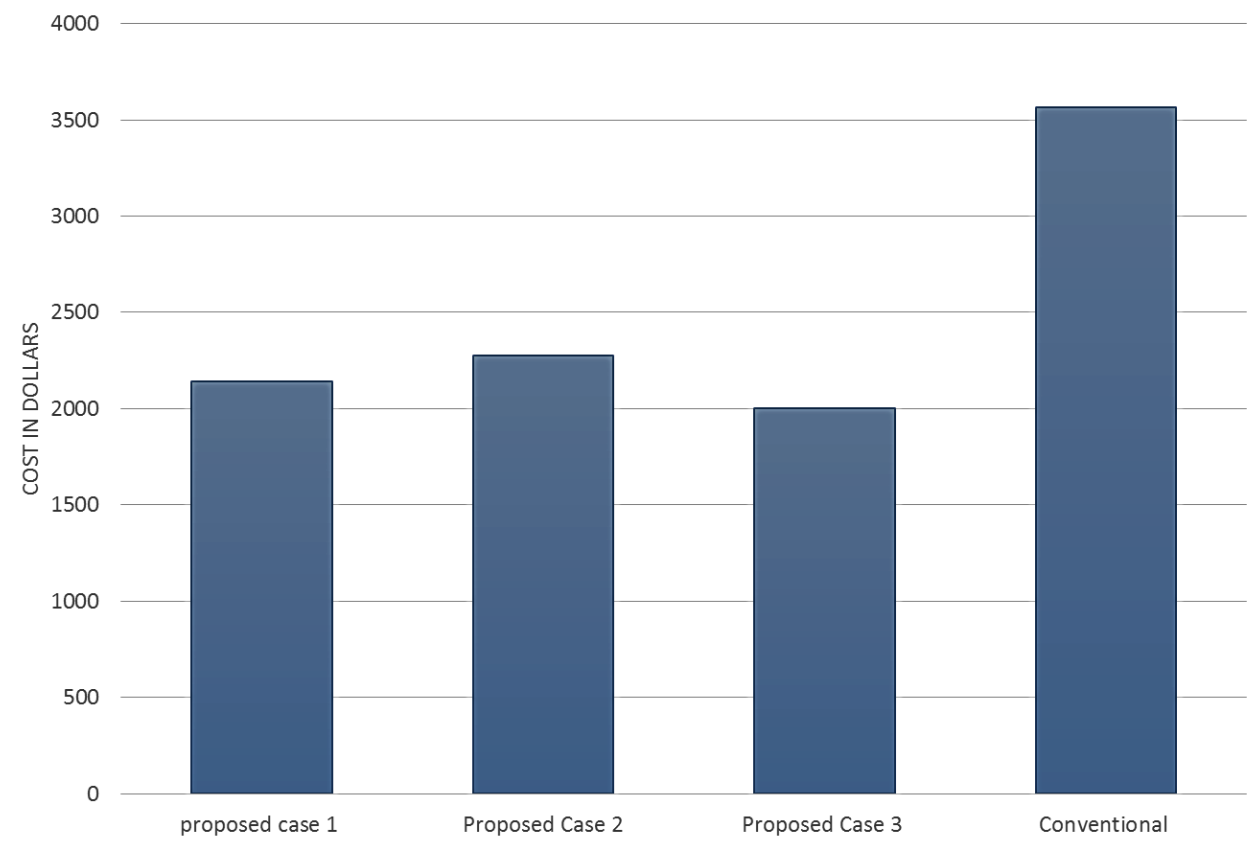

Figure.2 Cost Optimization

\section{Conclusion}

The optimization method developed applying the algorithm designed based on the fractional-Quadratic programming that is nonlinear, is basically to obtain the best outcomes for the FQTP. The algorithm mainly aims in minimizing the cost of transportation that is involved in the various applications, the numerical evaluation of the proposed algorithm was performed on the logistics of the goods dispatching company with three different source and the destination, the outcomes achieved in terms of optimal solution and cost showed that the proposed design outperforms the conventional. The procedure is basically used for identifying the best possible outcomes for the FQTP with stable cost either in the dimension of three or two. 
Journal of Soft Computing Paradigm (JSCP) (2020)

Vol.02/ No.02

Pages: $92-100$

http://irojournals.com/jscp/

DOI: https://doi.org/10.36548/jscp.2020.2.002

\section{References}

[1] Sivri, Mustafa, Ibrahim Emiroglu, Coskun Guler, and Fatih Tasci. "A solution proposal to the transportation problem with the linear fractional objective function." In 2011 Fourth International Conference on Modeling, Simulation and Applied Optimization, pp. 1-9. IEEE, 2011.

[2] Prakash, Satya. "A transportation problem with objectives to minimize total cost and duration of transportation." Opsearch 18, no. 4 (1981): 235-238.

[3] Basu, M., B. B. Pal, and A. Kundu. "An algorithm for the optimum time-cost trade-off in fixedcharge bi-criterion transportation problem bi-criterion transportation problem." Optimization 30, no. 1 (1994): 53-68.

[4] Schaible, Siegfried. "Fractional programming." In Handbook of global optimization, pp. 495608. Springer, Boston, MA, 1995.

[5] Charles, V., Venkata S. Sarma Yadavalli, M. C. L. Rao, and P. R. S. Reddy. "Stochastic fractional programming approach to a mean and variance model of a transportation problem." Mathematical Problems in Engineering 2011 (2011).

[6] Stancu-Minasian, Ioan M. Fractional programming: theory, methods and applications. Vol. 409. Springer Science \& Business Media, 2012.

[7] Ekezie, D. D., M. H. Ifeyinwa, and J. Opara. "Paradox in sum of a linear and a linear fractional transportation problem." Int. J. Appl. Math. Model. IJA2M 1, no. 4 (2013): 1-17.

[8] Kavita, Gupta, and Arora Shri Ram. "Linear Plus Linear Fractional Capacitated Transportation Problem with Restricted Flow." American Journal of Operations Research 2013 (2013).

[9] Narayanamoorthy, S., and S. Kalyani. "The intelligence of dual simplex method to solve linear fractional fuzzy transportation problem." Computational intelligence and neuroscience 2015 (2015).

[10] Smys, S., G. Josemin Bala, and Jennifer S. Raj. "Efficient topology control in wireless networks using minimum Backbone updates." In 2010 Second International conference on Computing, Communication and Networking Technologies, pp. 1-5. IEEE, 2010.

[11] Rahimunnisa, K. "Hybridized Genetic-Simulated Annealing Algorithm for Performance Optimization in Wireless Adhoc Network." Journal of Soft Computing Paradigm (JSCP) 1, no. 01 (2019): 1-13.

[12] Pandian, A. P. (2019). Artificial Intelligence Application in Smart Warehousing Environment for Automated Logistics. Journal of Artificial Intelligence, 1(02), 63-72.

[13] Ananthi, J. Vijitha, and Jennifer S. Raj. "A Peer to Peer Overlay Approach for Topology Maintenance in Wireless Networks." 
Journal of Soft Computing Paradigm (JSCP) (2020)

Vol.02/ No.02

Pages: $92-100$

http://irojournals.com/jscp/

DOI: https://doi.org/10.36548/jscp.2020.2.002

\section{Authors Biography}

Prof .Sathish works in the Department of EEE, in Eritrea Institute of Technology,Eritrea. His interested area of research includes modern computer Science and emerging smart technologies in various aspects of Wireless Communications, Cloud Computing, Computer System Engineering, Communication Technologies, Information Processing, Computer Networks, Web Technologies, Computing \& Communications, Automation, Image processing and Wireless Communications. 